\title{
Ten questions concerning wind-driven rain modeling in the built environment
}

\author{
Dominique Derome 1, Aytaç Kubilay 1, Thijs Defraeye 1,2, Bert Blocken 3,4, Jan Carmeliet 1,2 \\ 1 Laboratory of Multiscale studies in Building Physics, Empa, 8600 Dübendorf, Switzerland \\ 2 Chair of Building Physics, ETH Zürich, 8093 Zürich Hönggerberg, Switzerland \\ 3 Department of the Built Environment, Eindhoven University of Technology, P.O. Box 513, 5600 Eindhoven, The \\ Netherlands \\ 4 Department of Civil Engineering, KU Leuven, Kasteelpark Arenberg 40 - Bus 2447, 3001 Leuven, Belgium
}

\begin{abstract}
$\underline{\text { Abstract }}$
Wind-driven rain (WDR) in the built environment is a complex multiscale phenomenon. Wind flows in complex urban environment and rain events of various intensities may lead to very different rain deposition distributions within the city. Proper modelling of WDR is required as moisture is a main cause of material degradation in the built environment but also as understanding the water cycle in the urban environment is essential to provide solutions for the urban heat island, amongst others. What are the main aspects to be taken into account to predict wind-driven rain? How should such aspects be considered and modeled? Is it possible and relevant to predict in detail the moisture loads due to rain in complex systems as cities? This paper answers these questions from a multiscale perspective combining modeling and experimental work. The different scales relevant for accurate estimation of wind-driven rain in the built environment are presented. Rain deposition on complex geometries can be modeled by CFD, taking into account turbulent dispersion. Such modeling provides the impact velocity and angle of attack for each droplet size at any location on the urban surfaces. Using this information and the structure of the surface, the fate of the rain droplets can be predicted, namely whether it splashes, bounces or simple spreads.
\end{abstract}

$\underline{\text { Keywords }}$

Wind-driven rain, built environment, droplet trajectory, computational fluid dynamics (CFD), WDR catch ratio, droplet fate, porous materials

$\underline{\text { Introduction }}$

Rain in the built environment is a complex phenomenon which has impact on, amongst others, durability of the materials, vitality of urban vegetation, management of storm water and comfort, safety and health of the population. Not only does rain induce an environmental load on the surfaces it impacts, but, contrary to the other environmental loads of solar radiation and wind flow, a large part of the rain water remains present after the rain event and such presence must be accounted for despite the fleeting and stochastic nature of liquid flow. To properly capture rain, the different time scales of the phenomenon need to be considered. The first time scale is the few minutes rain droplets spend in the air before deposition. Air flow is drastically affected by the presence of buildings, influencing the distribution of rain load in the built environment. Then, the few milliseconds when droplets impact surfaces explain the different outcomes of spreading, splashing and/or rebound. The settlement of droplets on surfaces takes minutes, and the wetting of the surface and absorption in the porous media take several hours. In addition, as more and more droplets rest on a surface, they may coalesce and form a water film, resulting in rivulets and film run-off on the different surfaces. After a rain event, evaporation of the droplets and drying of the materials can take hours to days. As such rain deposition and the ensuing fate, i.e. the succession of subjected phenomena, of water is a multifaceted phenomenon which can be appropriately modeled at the different spatial and times scales due to recent computational advances.

A complete study of wind-driven rain (WDR) and the related moisture load on the urban environment takes into account WDR intensity as well as what happens after the impact of droplets. WDR is the type of rain, which is carried by wind and thus characterized by a horizontal velocity vector due to the effect of wind flow which affects the droplet trajectories. The horizontal component, $R_{w d r}$, of the oblique rain vector 
is the WDR intensity that causes a rain flux through a vertical plane, whereas the vertical component, $R_{h}$, is the rainfall intensity that causes a rain flux through a horizontal plane. WDR intensity is usually quantified with a catch ratio which normalizes the WDR intensity with the rainfall intensity:

$$
\eta_{d}(d)=\frac{R_{w d r}(d)}{R_{h}(d)}, \eta=\int_{d} f_{h}\left(R_{h}, d\right) \eta_{d}(d) \mathrm{d} d
$$

where $\eta_{d}(d)$ denotes the specific catch ratio which is related to raindrop diameter $d, \eta$ the catch ratio which is related to the entire spectrum of raindrop diameters, $f_{h}\left(R_{h}, d\right)$ the raindrop-size distribution through the horizontal plane. The distribution of catch ratios on building surfaces is influenced by building geometry, environment topography, position on the building facade, wind speed, wind direction, rainfall intensity and raindrop-size distribution (Choi 1993, Blocken and Carmeliet 2002). The resulting droplet impact speed and impact angle, together with the surface and material properties of building facades, govern the fate of the droplets after impingement on the facade, especially for droplet spreading (Lee et al. 2016a).

Different scales are involved in the distribution of WDR intensity within the built environment and the interaction of droplets with the built environment after impact. The principal features to be retained at these different scales and the relations between these features are discussed in this paper. The objective of this paper is to propose a global methodology to simulate rain entrained by wind within the built environment and to follow the fate of the deposited water. After a presentation of the physics and relevance of rain in Question 1, the methodology is presented through the answers of questions 2 to 8 . The need for such methodology and its future applications are discussed in the last two questions.

\section{Question 1: What is the relevance and significance of WDR in the built environment?}

WDR is one of the most important surface wetting and moisture sources on building facades (Blocken and Carmeliet 2004). Deterioration of building structures due to moisture usually begins in the regions where WDR impingement is the highest. Raindrops that strike and are deposited on a building surface can be absorbed or run off, both with potentially damaging consequences. As a result of absorption, rain water ingress is possible in case of an inadequate capillary break (Teasdale St-Hilaire and Derome 2007), in case of solid masonry, interior surface problems, such as mold growth, can arise due to moisture transported by capillary action (Hens 2010, Abuku et al. 2009b) or in case of wood-framed walls, by solar-induced thermal gradients (Carmeliet and Derome 2011a,b). As a result of run-off, water can leak into the building facade through cracks. Water in porous materials can lead to several undesired phenomena, such as frost damage on exterior wall surfaces (Van Balen 1996), erosion of building materials (Tang et al. 2004), moisture-induced salt migration (Charola and Lazzarini 1986), discoloration by efflorescence (Franke et al. 1998) and surface soiling (Etyemezian et al. 2000). Moreover, the conservation of historic buildings, the design of new buildings and the development of new building materials rely on the correct prediction of moisture loads (Briggen et al. 2009). The correct prediction of WDR is also significant in the assessment of environmental risks related to the leaching of harmful biocides and nanoparticles from buildings (Urkhardt et al. 2012). WDR deposition in the built environment sees these mentioned effects propagating through different urban surfaces, including, in addition to building facades, roofs, vegetated areas and paved streets, pedestrian ways, etc.

The distribution of surface wetting in the built environment is related to the interaction of raindrops of different size with wind flow. An overview of various relationships describing raindrop-size distributions is given by Uijlenhoet and Stricker (1999). Fig. 1(a) shows the raindrop size distribution through a horizontal plane based on the raindrop size distribution in the air, e.g. by Best (1950). For lower rainfall intensities, the probability distribution curve has a sharp shape and raindrops are of smaller size. As the rainfall intensity increases, larger raindrops tend to get more frequent and the probability distribution curve gets broader. The smallest size droplets in the spectrum can easily follow the vortical structures in the air flow around and between the buildings and hit shielded building facades due to their small inertia, 
while larger droplets are less influenced by wind flow patterns due to their inertia. As a result, different surface wetting patterns can be obtained at different rainfall intensities, even in identical wind flow conditions. Fig. 1(b) and (c) show the catch ratio distributions on the windward facade of a cubic building for a reference wind speed of $10 \mathrm{~m} / \mathrm{s}$ and for rainfall intensities of $1 \mathrm{~mm} / \mathrm{h}$ and $30 \mathrm{~mm} / \mathrm{h}$. For both rainfall intensities, the highest values are observed at the top corners due to the higher wind speed at higher heights along with the acceleration of the wind flow around the edges of the building. However, for the higher rainfall intensity, thus events with larger droplets, the wetting gradient gets smaller, with lower maximum catch ratio and higher minimum catch ratio. The distribution of surface wetting influences the wetting and drying conditions in the built environment. In particular, WDR analysis is required for the evaluation of mitigation solutions, relying on evaporative cooling, for local and urban heat islands in the built environment. Also, WDR distribution via its impact on local environment and building surface conditions is related to energy consumption of buildings and urban systems.

Given the large relevance and significance of WDR in the built environment, in the past years, several reviews on the topic have been published. Blocken and Carmeliet (2004) provided an extensive review of the history of wind-driven rain research, with specific focus on assessment methods such as on-site experiments, wind-tunnel experiments, semi-empirical formulae, WDR maps and numerical simulation based on Computational fluid dynamics (CFD). A later review by Blocken and Carmeliet (2010) focused in detail on the evaluation of three calculations models for WDR based on the model theory: the semiempirical model in the ISO Standard for WDR (ISO 2009), the semi-empirical model by Straube and Burnett (2000) and the CFD model by Choi (1993), extended by Blocken and Carmeliet (2002). This review highlighted the strengths and limitations of these models and their predictive capability, based on the extent to which the different influencing parameters of WDR are implemented in the models. More recent reviews can be found in Blocken et al. (2011), Moonen et al. (2012) and Blocken (2014).

a)

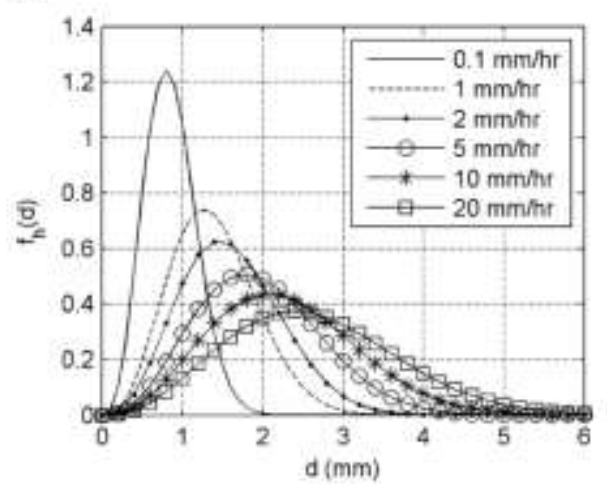

b)

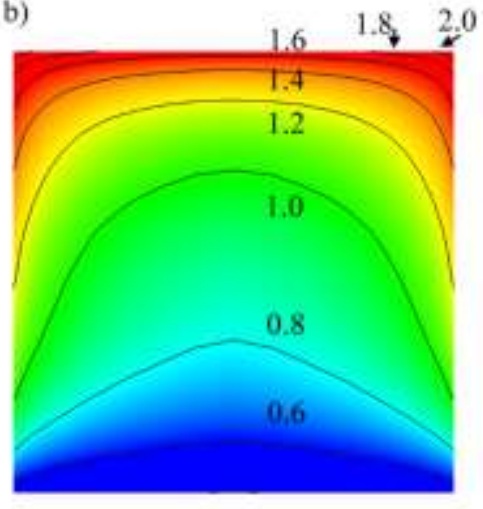

c)

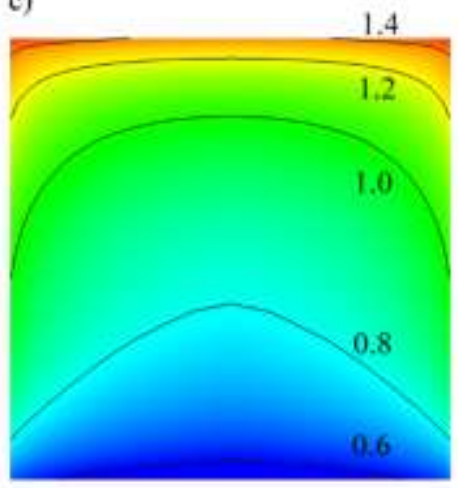

Fig. 1. a) Raindrop size distribution through a horizontal plane calculated from the raindrop diameter distribution in the air (based on Best 1950). Catch ratio distribution on the windward facade of a cubic building of size of $10 \mathrm{~m}$ for wind speed at cube height of $10 \mathrm{~m} / \mathrm{s}$ and rainfall intensity b) $R_{h}=1 \mathrm{~mm} / \mathrm{h}$ and c) $R_{h}=30 \mathrm{~mm} / \mathrm{h}$.

\section{Question 2: What are the most effective modes of investigation to properly capture WDR?}

Determining the distribution of WDR intensity can be performed with three general methods: experimental, semi-empirical and numerical methods. Field measurements of WDR on building facades are difficult to set up and time-consuming as they are confined to the meteorological conditions present at the time of experiments. Moreover, they are prone to errors mainly due to the uncertainties in measurement environment and measuring instruments (Blocken and Carmeliet 2005, 2006b; Högberg et al. 1999). Semi-empirical methods are, on the other hand, fast and easy to use. However, they are defined for specific building configurations and mostly do not take into account all relevant factors. Kubilay et al. (2014a) shows that the deviations between semi-empirical models and field measurements can be up to $88 \%$. Furthermore, various semi-empirical models can show differences of up to $300 \%$ (Blocken et al. 
2010; 2011; de Freitas et al. 2013; Kubilay et al. 2014a). Semi-empirical methods are generally suitable only for stand-alone buildings in simple configurations or for preliminary analysis. These methods will not give accurate results in cases of complex wind flow around multi-building configurations (Blocken et al. 2009). Besides, both measurements and semi-empirical methods are limited in terms of spatial resolution.

CFD simulations can be used to obtain accurate and detailed spatial and temporal information on WDR. Although CFD simulations can be complex and time consuming, they can be used for various types of rain events in much shorter times compared to experimental methods. Lagrangian particle tracking (LPT) models, combined with the steady Reynolds-averaged Navier-Stokes (RANS) equations, are the most commonly used method in the literature to estimate WDR intensity (Choi 1993; Lakehal et al 1995; Hangan 1999; Etyemezian et al. 2000; Blocken and Carmeliet 2002; van Mook 2002; Tang and Davidson 2004; Blocken and Carmeliet 2006a, 2007b; Briggen et al. 2009; Abuku et al. 2009a; van Hooff et al. 2011; Foroushani et al. 2014). One alternative to the LPT models is the Eulerian multiphase (EM) model (Huang and Li 2012; Kubilay et al. 2013), which can also be used to model the turbulent dispersion of raindrops with ease for time-averaged WDR calculations (Kubilay et al. 2015a). In the EM model, the rain is regarded a continuum, so similar to the gas phase, i.e. air. Further, different rain phases are considered for each class of raindrop sizes, as raindrops of different size will interact with the wind-flow field in a different way. Additional continuity and momentum equations are solved for each rain phase to obtain their phase fraction and velocity. The EM model results in less computational effort compared to LPT models (Kubilay et al. 2013) which require very high number of raindrops to achieve accurate results (Blocken and Carmeliet 2006a, 2007b), especially in the case of geometries with small details.

Furthermore, the EM model allows the estimation of the WDR intensity as well as the raindrop impact parameters, such as impact speed and impact angle, on all surfaces even in complex geometries (see Fig. 2 ). The time gain is evidently more significant for studies involving multiple buildings, e.g. an urban geometry, given the numerical model is validated for such geometries. On the other hand, LPT models offer a more straightforward approach for the droplet-wall interaction. Furthermore, care must be taken when using the EM model against numerical diffusion especially in regions with large gradients of rainphase fraction, e.g. in the presence of regions sheltered from rain. Nevertheless, the EM model is easier to deal with as the definition of boundary conditions is simpler. Validation studies for the EM model using data obtained from field measurements show that the average discrepancies of the results are between $2.5 \%$ and $12.0 \%$ for an array of cubic buildings (see Fig. 3 (Kubilay et al. 2014b)).

The efficiency of the EM model is especially significant as the distribution of impinging WDR intensity is necessary for more comprehensive studies of WDR. For example, in order to model a complete moisture redistribution in the urban environment, a multiscale approach is necessary. At the droplet scale, the fate of rain droplets after impingement is studied at the scale of a droplet based on the input coming from the WDR model. Droplet physics can be numerically modeled using methods such as the volume of fluid (VOF) (Lee et al. 2016b). At the built neighborhood scale, absorption in the built environment and the wetting and drying cycles of building materials are modeled. For this, heat and moisture transport in the built environment, i.e. building facades, ground, vegetation, are coupled with WDR intensity using building-envelope heat-air-moisture (BE-HAM) models (e.g. Janssen et al. 2007, Abuku et al. 2009b). 


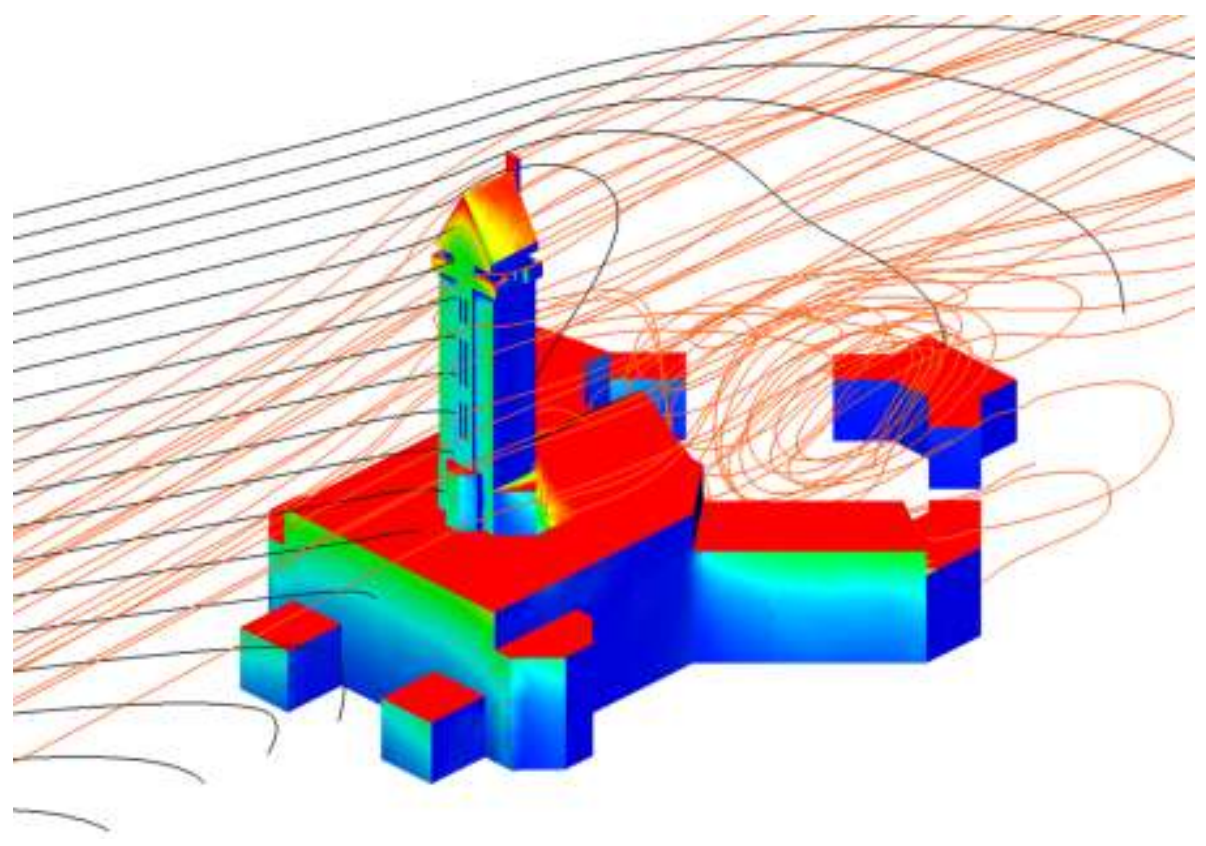

Fig. 2. Catch ratio on all the surfaces of a complex geometry together with streamlines of wind (orange) and rain (black) phases.
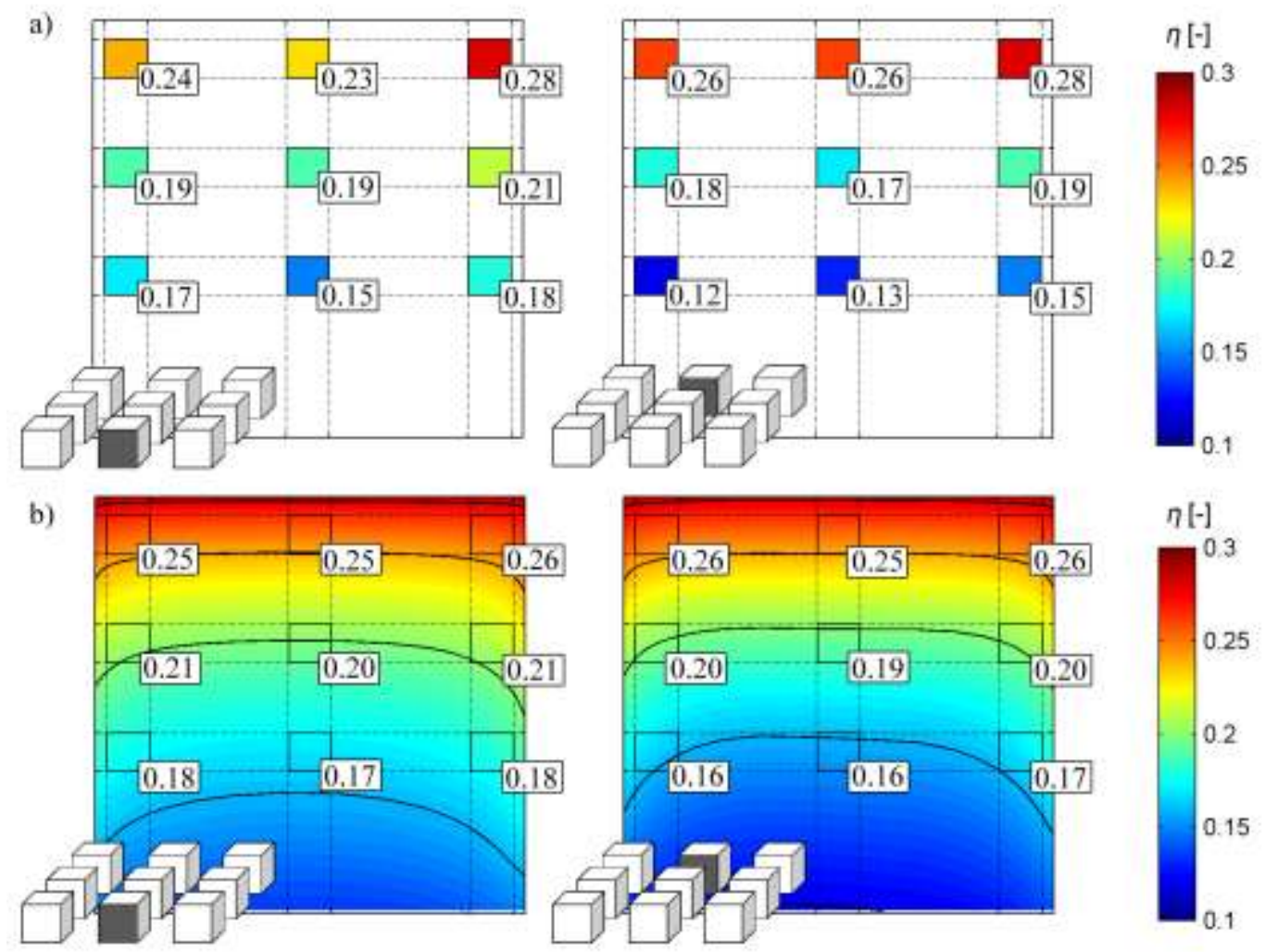

Fig. 3. Comparison of a) experimental and b) numerical catch ratios on two cubes of $2 \times 2 \times 2 \mathrm{~m}^{3}$ in an array of nine after a rain event on September 16-19, 2013, Dübendorf, Switzerland (Kubilay et al. 2014b). 
Question 3: Do we need time-resolved modeling of wind and of WDR?

The spatial and temporal distribution of WDR for transient rain events is commonly obtained based on steady-state simulations of wind and rain (Choi 1993; Blocken and Carmeliet 2002) that are combined with transient meteorological data records (Blocken and Carmeliet 2002). First, the spatial distributions of specific catch ratio for each raindrop size are determined. Second, the spatial distribution of catch ratio is calculated from the specific catch ratio and the horizontal intensity (Eq. (1)). This step creates a database of spatial catch ratio distributions for reference values of wind direction, wind speed and rainfall intensity. Finally, the catch ratio values are interpolated for a given position on the building using based on the experimental data records at each experimental time step. This approach is based on the assumption that the values calculated with steady-state airflow calculations for each experimental time step can capture the variations in the WDR intensity. The experimental time steps are mostly chosen to be 10 minutes, i.e. 10min averaged values for wind velocity and rainfall intensity, following the guidelines of van der Hoven (1957), Sumner (1981) and Blocken and Carmeliet (2007a, 2008) in order to minimize the errors related to the time resolution of meteorological datasets.

The validity of using steady-state calculations of WDR can be confirmed by comparison with unsteady calculations of WDR coupled with unsteady wind-flow simulations. WDR calculations with Large-Eddy Simulations (LES) give more insight in the transient behavior of raindrops such as the response of WDR on the local instantaneous wind flow around buildings. It is shown that wetting due to smaller droplets is dictated by the small-scale turbulent flow structures near buildings (Kubilay 2014, Kubilay et al. 2016b). On the other hand, the wetting due to larger droplets is mainly influenced by the large-scale wind-flow fluctuations above buildings (see Fig. 4(a)). Fig. 4(b) shows the numerical instantaneous specific catch ratio values for different raindrop sizes, as well as the running average catch ratio values over time (Kubilay 2016b). Both values are surface-averaged over 3 square-shaped small areas of $0.2 \times 0.2 \mathrm{~m}^{2}$ on the building representing WDR gauges on the windward facade of the cubic building. Fig. 4 shows that the variations of the specific catch ratio for instantaneous values is larger for the smaller raindrops of 0.3 $\mathrm{mm}$ diameter than it is for the raindrops of $2.0 \mathrm{~mm}$ diameter. Fig. 4 also shows that the running mean values of instantaneous specific catch ratio values are found to be stable after 100-200 s and agree well with the catch ratio values of the steady WDR. This comparison shows that the common practice of using the 10-min averaged meteorological data in steady-state WDR calculations is valid, assuming that the meteorological conditions such as wind direction and wind speed do not change significantly during this duration. 
a)

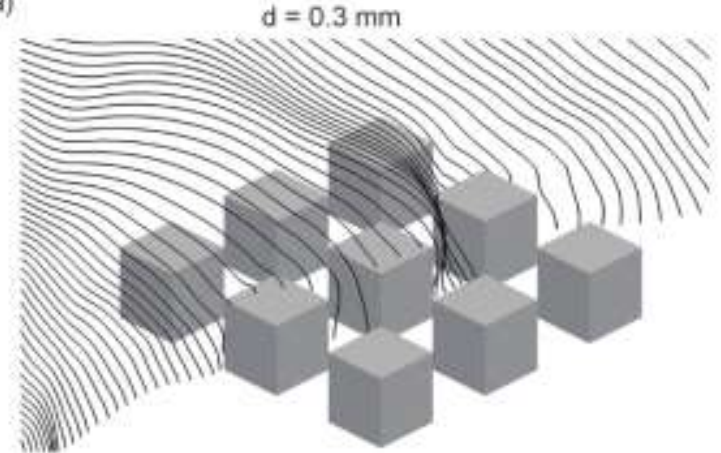

b)

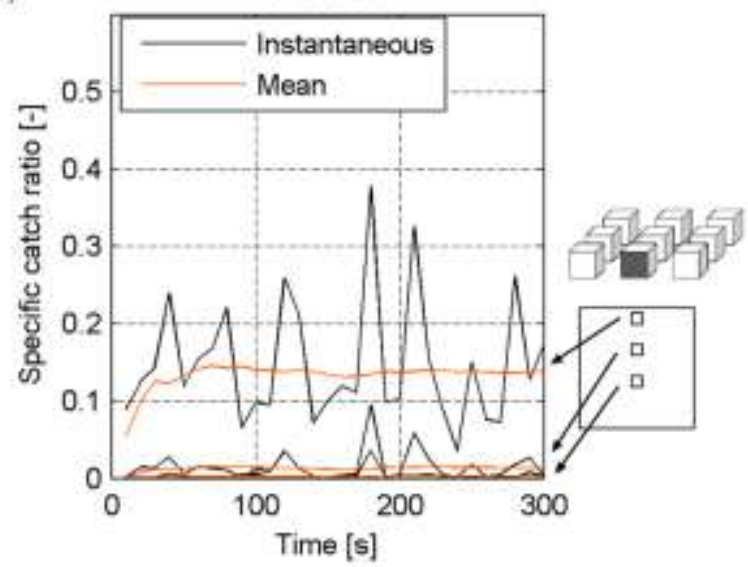

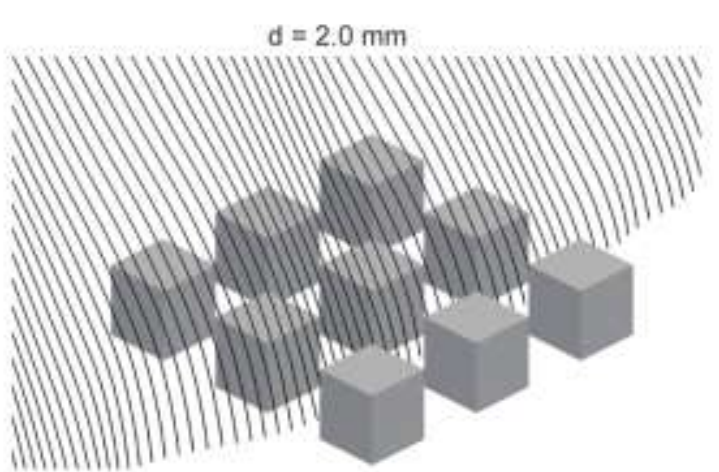

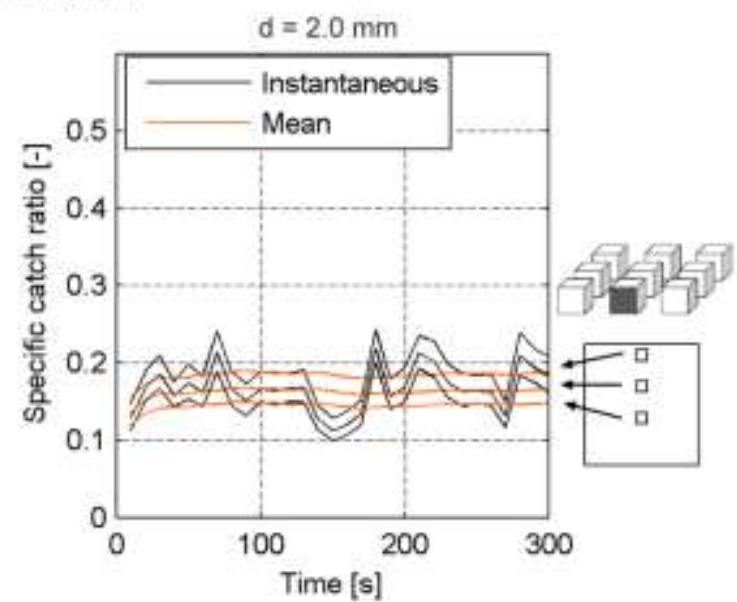

Fig. 4. a) Instantaneous streamlines with equidistant starting locations and b) instantaneous and running mean specific catch ratio, $\eta_{d}$, for raindrop sizes $d=0.3$ and $2.0 \mathrm{~mm}$ (based on Kubilay et al. 2016b).

\section{Question 4: Does turbulence play an important role?}

In certain cases, for example in presence of a standing vortex in front of the building, raindrop trajectories based on the mean wind flow can be nearly parallel to the building facade. Fluctuations in wind flow can then cause these raindrops to deviate from their mean trajectory and hit the facade. Lakehal et al. (1995) show that turbulent dispersion is an important factor which increases the WDR intensity on vertical walls in cases with low local wind speeds, such as in a street canyon. This work also shows that the effect of turbulent dispersion can be large and, in some cases, as important as the mean flow. Etyemezian et al. (2000) discuss that the effect of turbulence is not negligible for trajectories of individual drops but small when large surface areas of the building are considered, based on three raindrop sizes $(1.25 \mathrm{~mm}, 2.5 \mathrm{~mm}$ and $5 \mathrm{~mm}$ ). The paper does not explain the cause of this lower effect but, when considering a larger area, an equal amount of raindrops may be also diverted towards or away from the façade due to turbulent dispersion. Another reason could be the fact that the paper considers droplets of relatively large size. Nevertheless, in many numerical WDR studies, the influence of turbulent dispersion on WDR intensity is neglected, which may lead to erroneous results. Discrepancies between numerical and experimental data are largely attributed to neglecting turbulent dispersion, especially at lower parts of the buildings, as shown and discussed by Briggen et al. (2009). Neglecting turbulent dispersion is found to be a good approximation only for non-oblique flows on the windward facade of an isolated building with a small wind-blocking effect (Blocken and Carmeliet 2002, 2010; Choi 1997). The wind-blocking effect was first defined by Blocken and Carmeliet (2006a) as the upstream disturbance (slowdown) of the wind-flow pattern by the presence of the buildings having an important effect on WDR.

As long as the calculated wind-flow pattern is steady state, the trajectories of raindrops of the same diameter do not intersect each other. LPT models mostly calculate the WDR intensity based on the conservation of mass in stream-tubes formed between the individual trajectories of raindrops. However, 
this approach cannot be used when the wind-flow fluctuations are superimposed on the mean wind velocity. Instead, the use of time-varying wind-flow field requires even larger number of droplets to be injected and the number of droplets that hit the façade to be counted (Choi 1997, van Mook 2002). Furthermore, as the fluctuations superimposed on the mean wind velocity are stochastic, this approach requires a large number of simulation runs to get the correct WDR intensity distribution on the facade. On the other hand, Kubilay et al. (2015a) model the turbulent transport of raindrops with a more direct approach using the EM model. The resulting turbulent term in the momentum equation for the rain phases is expressed based on a response coefficient. The response coefficient models how droplets with different sizes are influenced by the fluctuations in the wind flow. The response coefficient is calculated using two time scales: 1) the particle relaxation time which is the rate of response of particle acceleration to the relative velocity between the particle and the carrier fluid; 2) the Lagrangian fluid time scale which is the characteristic large eddy lifetime. When the particle relaxation time gets smaller compared to the Lagrangian fluid time scale, as is the case for smaller raindrops, the response coefficient increases and the raindrops are more influenced by fluctuations in wind velocity. Fig. 5 compares the catch ratio charts with and without turbulent dispersion of raindrops at different positions on the windward facade of a high-rise building (Kubilay et al. 2015a). Ignoring turbulent dispersion leads to errors as high as $75 \%$ at high wind speed and low rain intensity, with average errors of $8 \%, 45 \%, 57 \%, 64 \%$ respectively for each position on Fig. 5.The influence of turbulent dispersion is more pronounced for low reference rainfall intensity and high reference wind speed values, and relatively more pronounced at lower parts of the facade. The model is validated using measurements on a monumental tower building, where the discrepancy between the numerical and measured values decreases considerably at the lower parts of the tower by modeling the turbulent dispersion of raindrops (Kubilay et al. 2015a).

a)

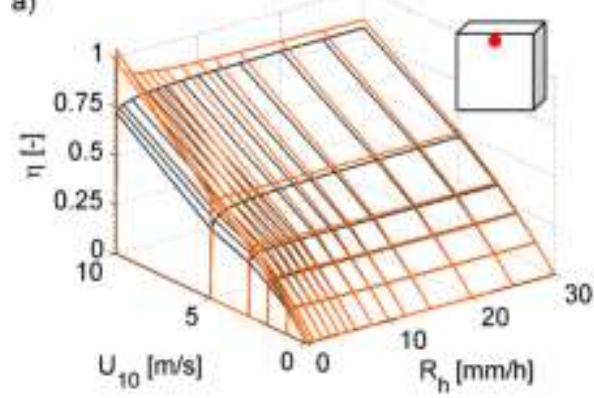

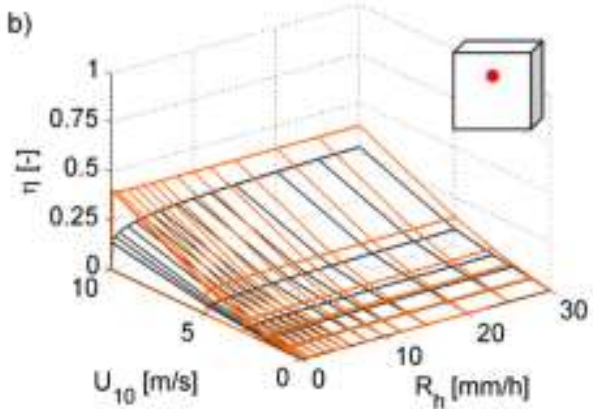

d)

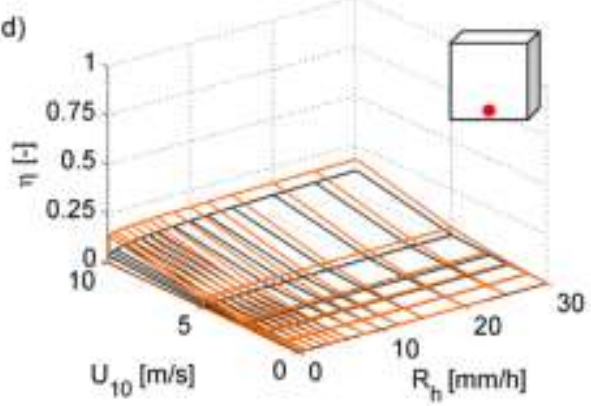

Fig. 5. Catch ratio charts (black: without turbulent dispersion, orange: with turbulent dispersion) on the windward facade for points at heights a) $y=50 \mathrm{~m}, \mathrm{~b}) \mathrm{y}=35 \mathrm{~m}, \mathrm{c}$ ) $\mathrm{y}=20 \mathrm{~m}$ and d) $\mathrm{y}=5 \mathrm{~m}$ for a building of dimensions $50 \mathrm{~m}$ high by $50 \mathrm{~m}$ wide (Kubilay et al. 2015a).

Question 5: How do building size, configuration and details influence WDR on building facades?

Wind-driven rain on buildings displays a wide range of deposition levels and deposition configurations of high complexity. While large areas of a building can be substantially sheltered from rain, the local rain intensity can be significantly higher than the horizontal rain intensity indicating a "concentration" of rain. In contrast, it is known from practice that small architectural details can have an important impact on 
WDR, preventing extreme wetting and moisture damage. We exemplify this diversity with two EM CFD studies including the effect of turbulent dispersion of raindrops.

First, two long parallel buildings with wind flowing normal to their length illustrate the impact of neighboring buildings and the role of the aspect ratio of buildings, as shown in Figure 6 . The results are presented in terms of normalized wind speed in the middle longitudinal plane of the computational domain and in terms of the rain catch ratio distribution over three surfaces of each building, calculated with a reference wind speed of $3 \mathrm{~m} / \mathrm{s}$ at $2.4 \mathrm{~m}$ height and a reference rainfall intensity of $1 \mathrm{~mm} / \mathrm{hr}$. Differences in wetting patterns are due to the effects of sheltering, wind-blocking effect and recirculation regions. The base case being the stand alone building (Fig. 6a), the presence of a low building upstream (Fig. 6b) is characterized by an acceleration of the flow above the tall building. The recirculation region between the two buildings leads to higher velocities than what is seen windward of the standalone building. These higher air flow rates result in the high building façade to be exposed to more WDR. Increasing the height of the first building (Fig. 6c) leads to a zone in between the buildings with little air movement and much less rain deposition over the height of the second building especially at its bottom part due to sheltering effect, as well as an increase of the gradient in rain deposition towards the roof top. Finally, increasing the width of the low front building (Fig. 6d) also has a very significant role in reducing rain deposition as, despite the low height of the front building, its width results in a large reduction of wind velocity upstream of the higher building, an illustration of the wind-blocking effect mentioned above. Thus, this simple parametric exercise on building geometry gives us the differences in WDR intensity, caused by a change of location and magnitude of recirculation zones, differential sheltering or wind-blocking effects and some acceleration of the wind, notably over the roof. Actually, as these factors that affect the catch ratio distribution can actually be conflicting with each other, only actual simulation of specific cases can elucidate the final WDR intensity due to these many factors. More on the validation of these results with field measurements can be found in (Kubilay et al. 2015b).

Next, we consider one building with façade modulations of increasing complexity to see the impact of small-scale façade features on rain deposition. In a first study, we vary the projection of the roof overhang. At higher rainfall intensities, the regions sheltered by the roof overhang decrease but increase with projection depth. In the second study, we add balconies and window sills on the façade. As the wind speed increases, the sheltering provided by roof overhang and balconies decreases as the raindrops move more horizontally. The catch ratios are compared for the surfaces of the windward facades in Fig 6e-f. It is clear that all projections, roof, balcony and even window sills, are effective at sheltering the facade from WDR, but in return these façade details themselves are exposed to a higher amount of WDR compared to the same location on the flat facade due to acceleration of wind flow around their edges. We note that the apparently small features that are window sills decrease the average catch ratio by $19 \%$ at the third floor and by $38 \%$ at the first floor for $U_{\text {ref }}=5 \mathrm{~m} / \mathrm{s}$ and $R_{h}=1 \mathrm{~mm} / \mathrm{h}$. They also decrease the average droplet impact speed for $1.0 \mathrm{~mm}$ droplets by $22 \%$ at the third floor and by $40 \%$ at the first floor for $U_{\text {ref }}=5 \mathrm{~m} / \mathrm{s}$. Finally, we also note that rain deposition on the ground around the building is significantly affected by the presence of the balconies. Further, Fig $6 \mathrm{~g}$-h illustrates this result showing the rain trajectories. More details on these results can be found in (Kubilay et al. 2016a). 

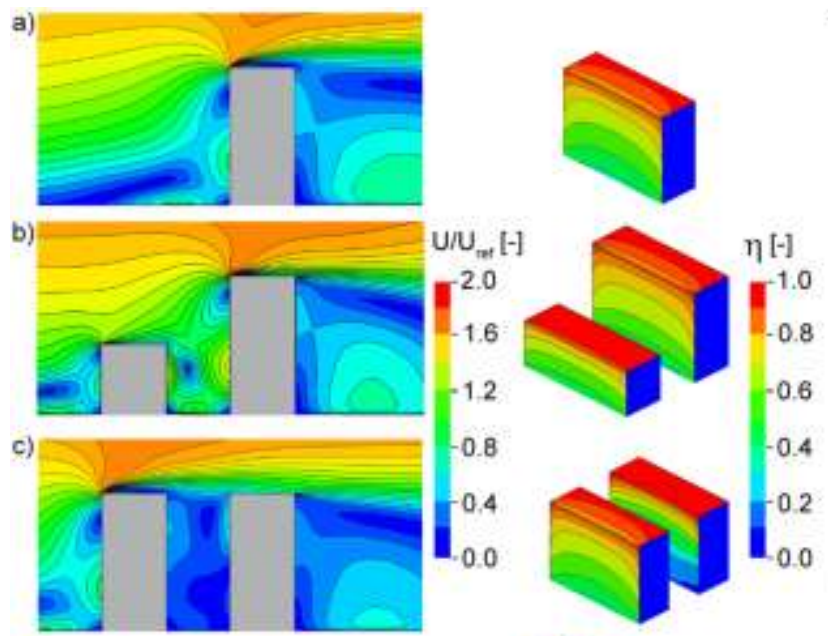

e)

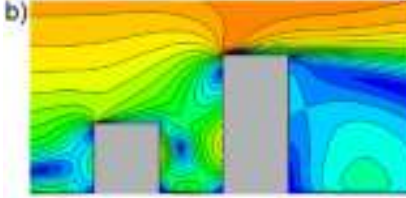

c)
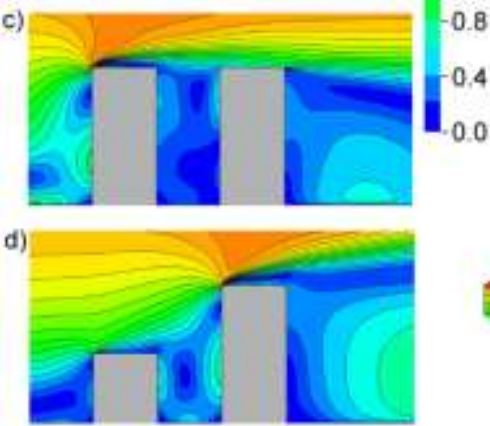

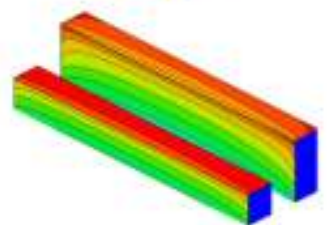

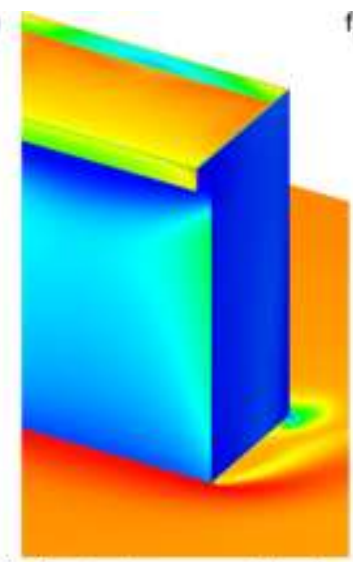

g) front view side view

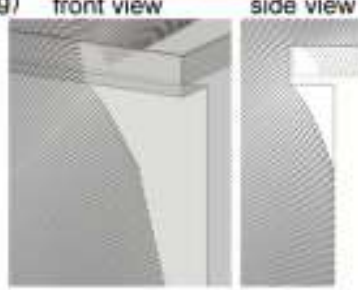

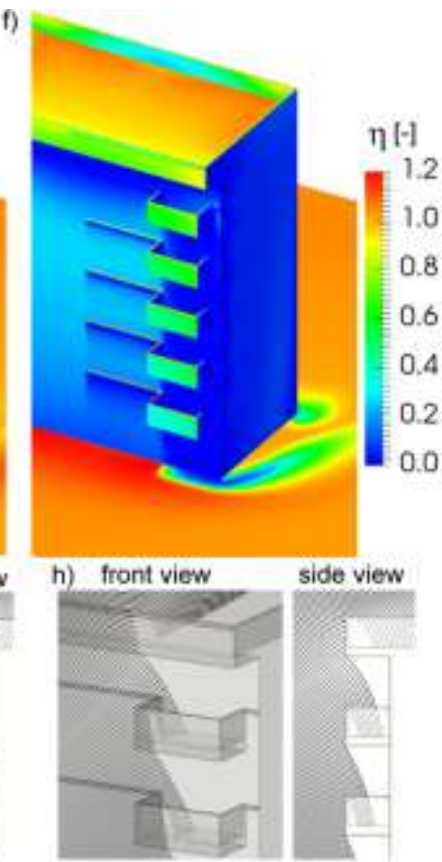

Fig. 6. a-d) Contours of normalized wind speed in the vertical centerplane and catch ratio on building surfaces for $U_{\text {ref }}=3 \mathrm{~m} / \mathrm{s}$ and $\mathrm{R}_{\mathrm{h}}=1 \mathrm{~mm} / \mathrm{h}$ comparing different configurations (Kubilay et al. 2015b) e-f) Contours of catch ratio and raindrop trajectories comparing buildings with flat façade and façade details for $U_{\text {ref }}=5 \mathrm{~m} / \mathrm{s}$ and $R_{h}=1 \mathrm{~mm} / \mathrm{h}$. (Kubilay et al. 2016a), g-h) Front and side view of rain droplet streamlines on the façade in the absence or presence of balconies for $U_{\text {ref }}=5 \mathrm{~m} / \mathrm{s}$ and $R_{h}=1 \mathrm{~mm} / \mathrm{h}$. (Kubilay et al. 2016a).

\section{Question 6: How do rain droplets interact with impervious surfaces?}

The previous sections have demonstrated how diverse rain deposition configurations can be and how the EM CFD methodology described above can adequately predict WDR on built systems of increasing complexity. Of further interest now is that such simulations can provide also the impact velocity and angle of attack of any droplet for any location within the simulated built environment. These parameters are important since they determine droplet behavior like spreading and splashing. Using the 6-storey high building with balconies of the previous section as an illustration, Figure 7 plots impact speed and angle of attack for $1 \mathrm{~mm}$-diameter droplets with a reference wind speed of $5 \mathrm{~m} / \mathrm{s}$. The impact speed in the direction of the trajectory can vary from null to above $7 \mathrm{~m} / \mathrm{s}$ while the angle of attack is overall very low, i.e. almost parallel to the surface, explaining the very low catch ratio seen in Fig. 6. However, at the top of the building, due to the wind-flow pattern, droplets can come in contact with the parapet at angles of attack near $90^{\circ}$.

a)

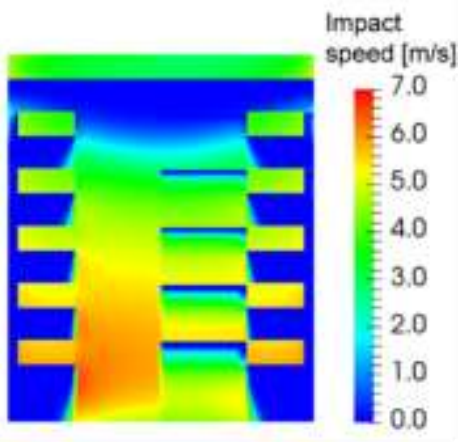

b)

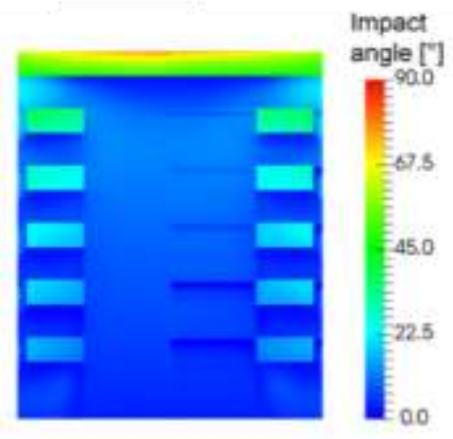

Figure 7. Contours of droplet impact a) speed and b) angle for raindrop of $1.0 \mathrm{~mm}$ diameter and wind speed of $U_{\text {ref }}=5 \mathrm{~m} / \mathrm{s}$ (Kubilay et al. 2016a). The droplet impact angle is the angle between the droplet trajectory at impact and the building surface. 
From their impact speed, $V_{i}$, and angle and their mass (often reported in terms of size or diameter), the fate of droplets can then be determined. Figure 8 illustrates the different outcomes of a water droplet impacting an impervious flat surface at $90^{\circ}$ for different impact speeds in the 0.1 to $3 \mathrm{~m} / \mathrm{s}$ range. At low impact speed, the droplet spreads and recedes until equilibrium on the surface. At higher velocity, the droplet may produce a daughter droplet during the receding phase. At even higher velocity, the spreading departs from a circular shape and fingering may occur, also possibly leading to break-up of these fingers and the formation of several droplets at equilibrium. Starting from around $3 \mathrm{~m} / \mathrm{s}$, splashing may occur, a stochastic phenomenon where fractions of the droplet detach into smaller droplets which are propelled further from the impact point. The prediction of the different outcomes after droplet impact has been the object of several empirical, analytical or numerical models. The spreading of a water droplet on an impervious surface is discussed here for the range of impact velocity lower than $3 \mathrm{~m} / \mathrm{s}$, thus before splashing, while impact on porous media is discussed in the next question.

The maximum spreading ratio is defined as

$$
\beta_{\max }=D_{\max } / D_{0}
$$

where $D_{\max }$ is the maximum spreading diameter and $D_{0}$ the initial drop diameter prior to impact. A large number of parameters, such as droplet size, impact velocity, liquid properties (density $\rho$, viscosity $\mu$ and surface tension $\gamma$ ), surface roughness and wettability, plays a role in the maximal spreading achieved by a droplet. Spreading is governed by the balance between kinetic, capillary, and viscous energy, where the kinetic energy is given by $E_{k}=\rho D_{0}^{3} V_{i}^{2}$, the capillary energy by $E_{\gamma}=\gamma_{L V} D_{0}{ }^{2}$ and the viscous energy by $E_{\mu}$ $=\mu V_{i} D_{0}{ }^{2}$. Most of the existing models are formulated based on two dimensionless parameters: Weber number $\left(W e=\rho V_{i}^{2} D_{0} / \gamma\right)$, which is the ratio between the kinetic and capillary energy, $E_{k} / E_{\gamma}$, and Reynolds number $\left(\operatorname{Re}=\rho V_{i} D_{0} / \mu\right)$, which is the ratio between the kinetic and viscous energy, $E_{k} / E_{\mu}$. In Lee et al. (2016a,c), a universal scaling to predict maximum spreading between two asymptotic behaviors, based on Laan et al. (2014) and using the Weber and Reynolds numbers, takes into account low impact speeds by correcting with a spreading ratio of the droplet at very low impact speed, $\beta_{V i=0}^{2}$ :

$$
\left(\beta_{\text {max }}^{2}-\beta_{V i=0}^{2}\right)^{1 / 2} \cdot R e^{-1 / 5}=W e^{1 / 2} /\left(A+W e^{1 / 2}\right)
$$

where the factor A is 7.6. This scaling law allows to predict the maximal spreading when the impact speed and impact angle are known (see Fig. 9b). On impervious surfaces and independently of the presence of surface features or roughness, there is a receding phase after maximum spreading. At equilibrium, the droplet final contact area with the surface lies between the maximum spreading area and the sessile droplet equilibrium, depending on the wettability of the surface. For droplets impacting under an impact angle different from zero, the contact area is elongated along the projected direction of the impact velocity.

The final shape of the droplet on dry or wet surfaces, and as well its dependency on the orientation of the surface (horizontal, vertical or inclined) has been taken into account in a first attempt by (Abuku et al. 2009a) and by the model of (Laan et al. 2014) and a correction for impact angle. However, a full characterization of the fate of droplets for the range of impact speed and angle seen during rain events has yet to be developed. 


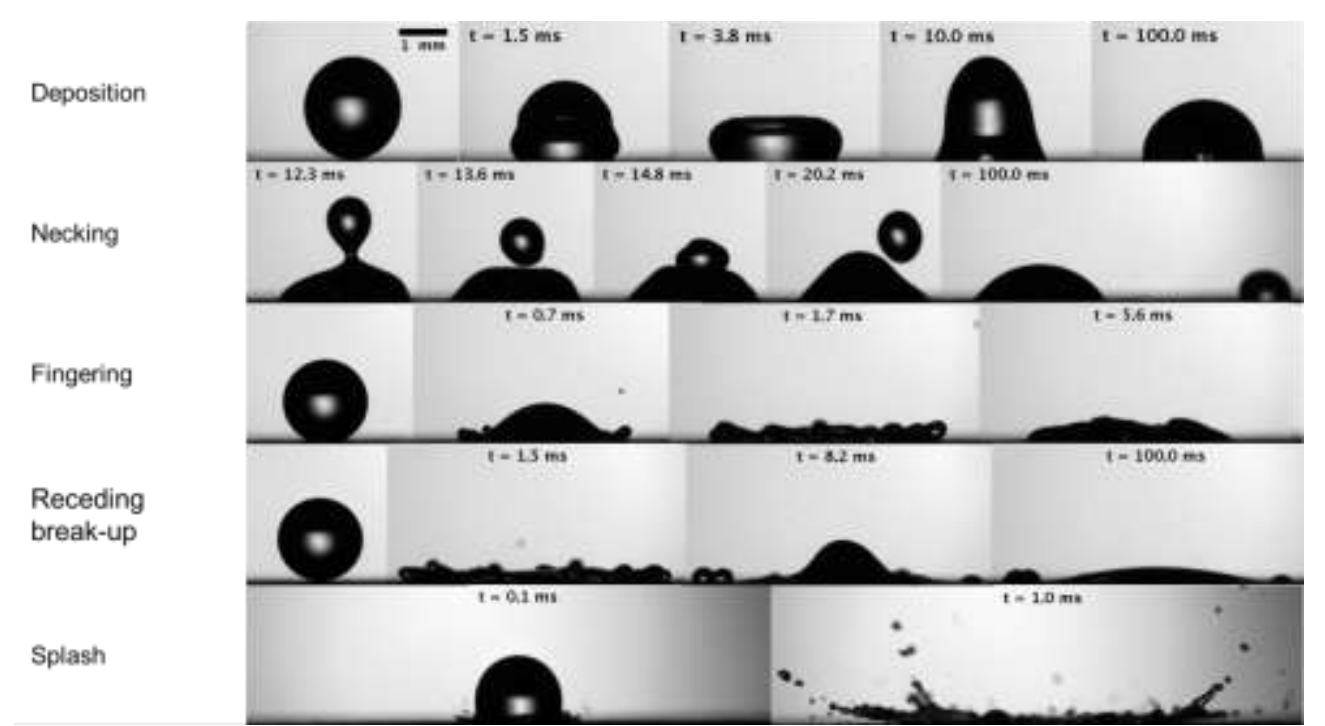

Fig. 8 High-speed images from droplets impacting an impervious surface at different impact speeds and the resulting variants of fate.

\section{Question 7: How do rain droplets interact with porous materials?}

A high fraction of materials lining the urban environment are porous, such as brick and mortar, concrete, wood, porous asphalt and soils. As observed above for impact on impervious surfaces, droplets impacting porous media will also undergo a different fate depending on impact velocity and angle. In addition, the life of such droplets will be influenced by an additional phenomenon, namely absorption into the porous material. In a recent work on droplet impact and absorption on three sedimentary stones, different time scales are identified using high-speed shadowgraphy and neutron radiography (Lee et al. $2016 \mathrm{~d}$, e and Figure 9). Right after drop impact, the droplet spreads. A dynamic contact angle higher than $90^{\circ}$ is observed indicating a dynamic non-wetting behavior. High spatial- and time-resolution investigation of this dynamic phase has led to the observation that no liquid mass penetrates into the porous substrate during spreading. As the contact line reaches maximum spreading, the droplet contacts the porous substrate and is pinned at its edges. The maximum spreading diameter on porous media can be determined using Equation 3, as shown in Figure $9 \mathrm{~b}$ by comparing measurements on steel and on three sedimentary stones (Lee et al. 2016d).

Once the water-porous medium contact is established, absorption of the liquid within the porous medium is initiated (Fig 9a). In comparison with spreading that occurs over a few milliseconds, absorption can take seconds to minutes depending on the porous medium. During the absorption, the droplet remains pinned with constant contact radius and the contact angle decreases in a constant contact area radius mode for the materials that were considered. The mass absorbed in the stone increases until the droplet is depleted and this rate of droplet absorption and depletion occurs obviously faster in highly capillary active stones. Once the droplet is depleted, water evaporation at the medium surface and further redistribution of moisture within the medium are observed.

As mentioned above, higher impact speeds result in larger spreading ratios. Therefore the resulting pinned contact area at maximum spreading also influences the rate of droplet depletion and hence the rate of evaporation. Thus wetting of porous materials depends on the impact speed and angle, although little work has yet investigated the proper characterization of this wetting-drying behavior and its dependence on WDR parameters. The contact area of droplets impacting with an impact angle is elongated along the projected direction of the impact velocity and the length of contact area is traditionally estimated using the cosine of the impact angle (Laan et al. 2015). This approach is used for water droplet impingement on a brick in Abuku et al. (2009c). 
Droplets impacting dry porous materials tend to pin at maximum spreading. Droplets impacting on an already wetted or partially wetted surfaces can exhibit much higher spreading, although often pinning is not observed on a wetted surface.

a)

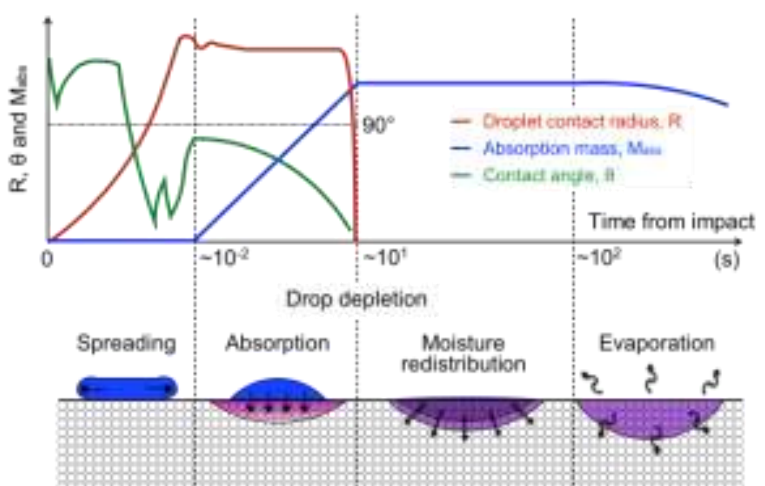

b)

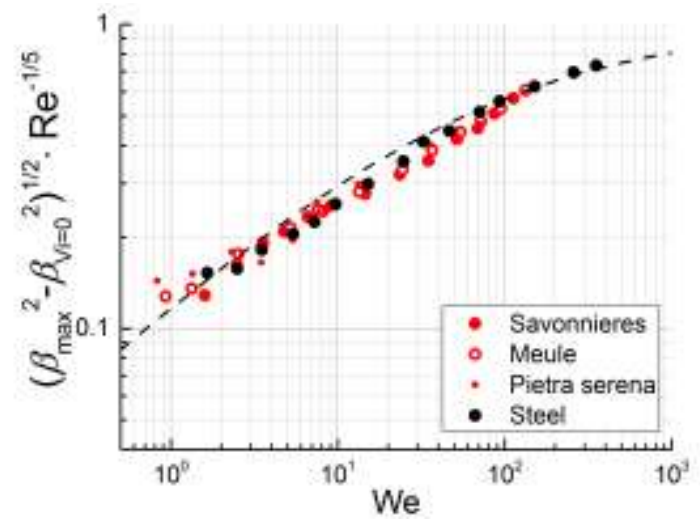

Fig. 9 a) Schematic representation of the fate of a droplet impacting a porous material. b) Comparison of measurement of maximum droplet radius impacting three porous stones with different porosity and capillary absorption characteristics and steel with equation 3 (based on Lee et al. 2016 d, e).

\section{Question 8: How does a surface become wet during a rain event?}

The two previous questions focused on the impact of a single droplet. However, rain events consist of extremely large quantities of rain droplets, thus large series of deposition of discrete amounts of water, i.e. droplets, on the surface (Abuku et al. 2009b). During such multi-droplets events, the surface evolves from dry to wet. Several post-deposition phenomena can occur, i.e. droplet coalescence, film forming and film runoff, plus absorption in the material.

Coalescence of droplets can occur at different stages: one droplet impacts on a surface already holding a deposited droplet, droplets deposited on a hydrophilic surface undergoing hemiwicking until they touch each other, etc. Once coalesced, the new configuration of the larger droplet is yet to be defined.

As multiple droplets coalesce on impervious surfaces, they start to form a film. For porous surfaces, film forming may occur only after a sufficient amount of water is adsorbed in the material. On vertical or inclined surfaces, such thin water films run off under the force of gravity, but are counteracted by wall shear and surface tension. Depending on the film and surface characteristics, different run-off patterns appear along the water-surface-air contact line. Often fingers are formed in the contact line as the film progresses, due to instabilities developing in the film, leading to locally higher water speed and volume flow rates. At sufficiently high run-off speeds, waves can appear in the film running down.

To quantify gravity-driven film dynamics during run-off, analytical solutions can be used, in particular the Nusselt solution which has been frequently applied in WDR studies (Blocken \& Carmeliet, 2012; Blocken et al., 2013; Van den Brande et al. 2013). More advanced alternatives include a weighted-residual model (Ruyer-Quil \& Manneville, 2000, 2002). For film flow over large surfaces with a complex geometry, such as in WDR applications, CFD modeling is more appropriate. The thin-film approximation, often applied (Martin et al. 2015), simplifies the problem by not discretizing the film over its thickness. As such, only one computational cell over the film height is assumed. Such models capture accurately the film characteristics, such as film speed and thickness, contact line dynamics as well as wave formation and propagation as shown in Figure 10 and comparing with experimental results from (Silvi, 1985). Although a lot of research has been performed on film flow running down inclined surfaces, the specific challenge for WDR research is that several independent films may form at many locations on the building facade at same time. For WDR applications, particularly interactions of multiple films and their fingers are a future 
focus point. Furthermore, how to upscale the movement of these multiple film flows to the entire building level in continuum modelling is also a challenge, not mentioning accounting that all these film flows from the urban surfaces eventually collect water to roof drains, storm water systems, etc.

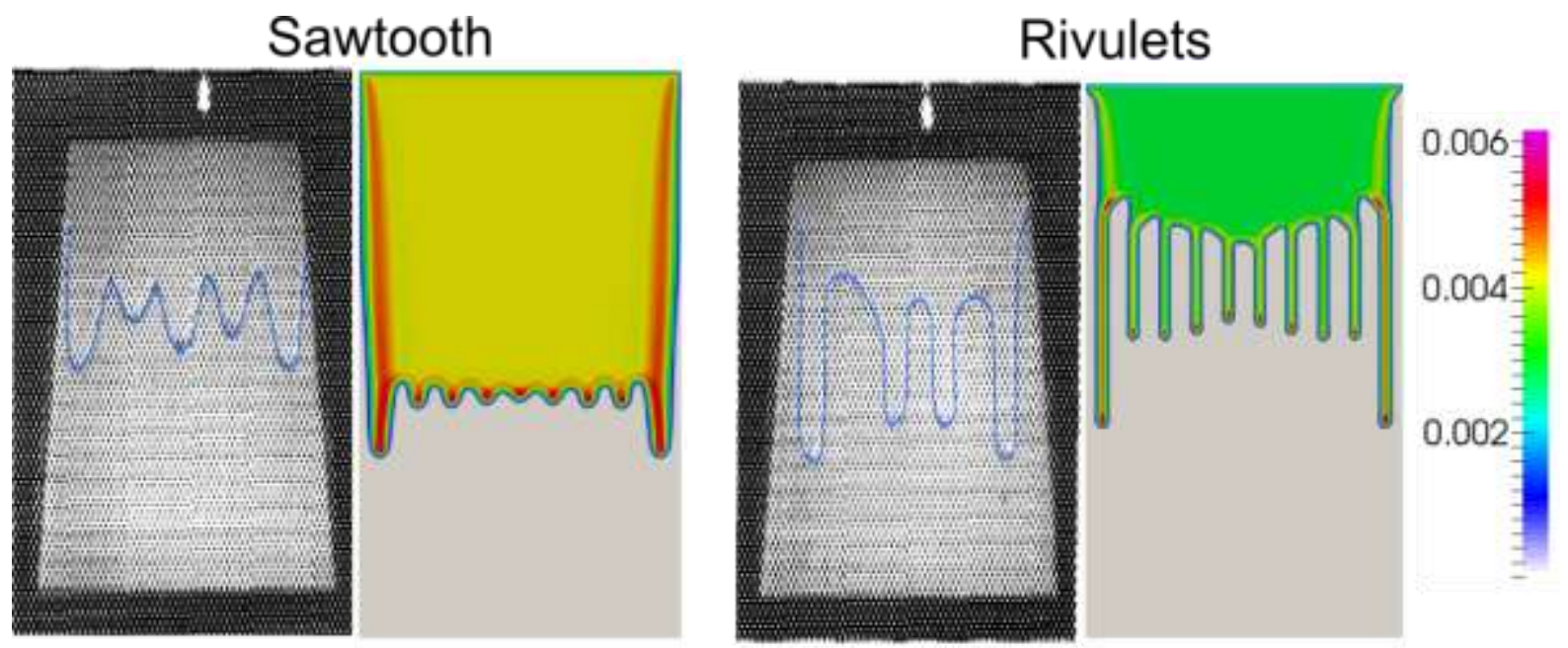

Fig. 10 Modeling results of instantaneous glycerin film thickness (color) and from the figures derived from the experiment (black-white) of glycerin film at $22^{\circ} \mathrm{C}$ flowing down a $84^{\circ}$ inclined glass surface at $105 \mathrm{~s}$ (left) and on an inclined PMMA surface at $120 \mathrm{~s}$ (right) (Martin et al. 2015).

Question 9: Which accuracy of WDR is needed for hygrothermal performance and durability analysis?

Currently, in studies of assessment of the hygrothermal performance of the built environment subjected to environmental loadings and in evaluation of durability and risk of deterioration, WDR intensity is used as the moisture load due to rain for building surfaces. In fact, in such studies, WDR intensity is often considered uniform across large parts of the façade (as per ASHRAE standard (ASHRAE 2009) and International standard (ISO 2009)). Such simplistic uniform WDR loading leads to discrepancies with reality as a typical surface wetting pattern shows large gradients both vertically and horizontally, even in the simplest cases of isolated buildings, as discussed above. In multi-building configurations, the windflow pattern around one building is further influenced by other buildings and becomes more complex (Blocken et al. 2009; Kubilay et al. 2015b). Finally, small-scale facade details also have a considerable impact on WDR intensity, droplet impact speed and impact angle. To understand the impact of WDR thus requires more detailed spatial and temporal information.

Thus, there is a crucial need to assess the hygrothermal performance and durability of building envelope under more representative WDR conditions. Actually, WDR presents a multiscale challenge and recent progress in research has been made across the scales, as presented above. In addition to the adequate capturing of the physics at the different length and time scales, an important part of the challenge lies in the appropriate methodology required to "connect" all scales. In terms of hygrothermal performance, such multiscale methodology to determine the actual moisture load on the materials due to WDR, including the water films sitting or draining on the surfaces, is required, with the main existing roadblocks remaining namely on how to couple large domains used in WDR-CFD with single droplet physics, in order to predict deposited amount while accounting for depletion due to adsorption or to runoff of water. Once actual moisture loads are known, then the hygrothermal response of materials can be assessed. There are few examples of assessment methodologies accounting for the sensitivity to material input or environment loading, although (Carmeliet et al. 2009) provides a demonstration on the use of stochastics. Eventually, the required level of certainty or accuracy of WDR inputs could be evaluated, by testing variable WDR load with simulations and assessing the impacts. 
Question 10: How to approach the link between WDR, vegetation and urban microclimate?

It is expected that European summer climates may experience a pronounced increase in climate variability and incidence of heat waves in response to climate change, which will represent a serious challenge to formulate adaptive response strategies to cope with these changes (Schär et al. 2004, Fischer and Schär 2009). Especially urban areas may be affected, since, in addition, these regions may already experience urban heat island effects, characterized by higher air temperatures compared to the surrounding rural environment (Oke 1987). The urban heat island effect, characterized by higher air temperatures compared to the surrounding rural environment, threatens seriously future urban comfort, inhabitant health and building energy consumption and is considered as one of the major problems in the 21 st century posed to human beings. Due to the severity of the problem, major research initiatives have been directed to a better understanding of the physics of the urban climate with the aim of proposing mitigation measures. Building materials that are common in the built environment, e.g. concrete, asphalt, brick, but also vegetation, e.g. grass, small plants, trees, significantly influence the absorption, transport and storage capacity of heat and moisture in the built environment. This storage capacity influences the heating and cooling of the built environment significantly and has to be taken into account in urban heat island studies. Furthermore, it is known that the temperature difference between air and building surfaces, as well as the approach wind speed, has a significant effect on the air flow regime, being forced, mixed or natural convection. However, numerical studies of urban microclimate often simplify the sources of moisture and the coupling of moisture and heat transport occurring at the urban surfaces and in the urban materials. The influence of moisture transport within materials/surfaces on the complex behavior of microclimate is yet to be fully understood. In order to capture the influence of WDR and moisture on urban microclimate, a fullyintegrated 3D numerical urban microclimate model is necessary, which takes into consideration wind flow, temperature and relative humidity for air, temperature and moisture content in building and urban materials, and direct and diffuse solar radiation as well as thermal radiation with reflections.

WDR intensity is also required as it is an important boundary condition in studies on the water cycle in the built environment, particularly when studying the cooling effect due to evaporation in the built environment (Kubilay et al. 2016c). In this perspective, it is important to note that wind influences as well the WDR amount, as well as phenomena like evaporative cooling and heat removal by buoyancy. Two main gaps should be addressed for the success of such studies: deposition and absorption of WDR on porous urban surfaces as well as the fate of droplets on impervious surfaces, including vegetation (grass, small plants, trees), and role of WDR in the urban water cycle.

\section{Conclusion}

Wind-driven rain (WDR) in the built environment is definitely a complex phenomenon with multiscale ramifications. Wind flows in complex urban environment and rain events of various intensities may lead to very different rain deposition patterns across the city, from neighborhood to neighborhood, or from building to building. Thus, different scales have to be taken into account for an accurate estimation of wind-driven rain in the built environment, ranging from the neighborhood scale to droplet impact phenomena. Rain deposition on complex geometry can be modeled by CFD, taking into account turbulent dispersion. Such modeling provides the impact velocity and angle of attack for each droplet size at any location in the domain. The fate of the rain droplets on the different surfaces of the built environment can be predicted using impact velocity, angle of attack and the nature of the surface. Properly modeling WDR is required as moisture is a main cause of degradation in the built environment but also as understanding the cycle of water in the urban environment may provide paths of solutions for, e.g. urban heat island effects. In this paper, we have particularly stressed the multiscale nature of the WDR deposited within an urban environmental. This multiscale nature is reflected by the different modeling approaches developed and the dire need of the properly assessing the different physics, linking them and the unresolved challenge of properly upscaling between scales has been particularly underlined. 
Acknowledgments

We acknowledge the important contribution of the $\mathrm{PhD}$ work of Jae Bong Lee to this paper. His PhD and the $\mathrm{PhD}$ of Aytaç Kubilay was made possible through Swiss National Science Foundation project no. 200021-135510. The work on run-off was support through Swiss National Science Foundation project no. 200021-132001. Bert Blocken acknowledges the IWT-Flanders that funded his PhD research on winddriven rain and the FWO-Flanders (Research Fund Flanders) for financially supporting his postdoctoral research on this topic.

\section{$\underline{\text { References }}$}

Abuku, M., Blocken, B., Nore, K., Thue, J.V., Carmeliet, J., Roels, S. 2009a. On the validity of numerical winddriven rain simulation on a rectangular low-rise building under various oblique winds. Build Environ 44 (3):621-632.

Abuku, M., Janssen, H., Roels, S. 2009b. Impact of wind-driven rain on historic brick wall buildings in a moderately cold and humid climate: Numerical analyses of mould growth risk, indoor climate and energy consumption. Energ Buildings 41 (1):101-110.

Abuku, M., Blocken, B., Roels, S. 2009c. Moisture response of building facades to wind-driven rain: field measurements compared with numerical simulations. J Wind Eng Ind Aerod 97(5-6): 197-207.

ASHRAE 2009. Standard 160-2009 Criteria for Moisture-Control Design Analysis in Buildings, ASHRAE.

Best, A.C. 1950. The size distribution of raindrops. Q J Roy Meteor Soc 76 (327):16-36.

Blocken, B. and Carmeliet, J. 2002. Spatial and temporal distribution of driving rain on a low-rise building. Wind Struct 5 (5):441-462.

Blocken, B. and Carmeliet, J. 2004. A review of wind-driven rain research in building science. J Wind Eng Ind Aerod 92 (13):1079-1130.

Blocken, B. and Carmeliet, J. 2005. High-resolution wind-driven rain measurements on a low-rise building experimental data for model development and model validation. J Wind Eng Ind Aerod 93 (12):905-928.

Blocken, B. and Carmeliet, J. 2006a. The influence of the wind-blocking effect by a building on its wind-driven rain exposure. J Wind Eng Ind Aerod 94 (2):101-127.

Blocken, B. and Carmeliet, J. 2006b. On the accuracy of wind-driven rain measurements on buildings. Build Environ 41 (12):1798-1810.

Blocken, B. and Carmeliet, J. 2007a. On the errors associated with the use of hourly data in wind-driven rain calculations on building facades. Atmos Environ 41 (11):2335-2343.

Blocken, B. and Carmeliet, J. 2007b. Validation of CFD simulations of'wind-driven rain on a low-rise building facade. Build Environ 42 (7):2530-2548.

Blocken, B. and Carmeliet, J. 2008. Guidelines for the required time resolution of meteorological input data for wind-driven rain calculations on buildings. J Wind Eng Ind Aerod 96 (5):621-639.

Blocken, B., Dezso, G., van Beeck, J. Carmeliet, J. 2009. The mutual influence of two buildings on their wind-driven rain exposure and comments on the obstruction factor. J Wind Eng Ind Aerod 97 (5-6):180-196.

Blocken, B. and Carmeliet, J. 2010. Overview of three state-of-the-art wind-driven rain assessment models and comparison based on model theory. Build Environ 45 (3):691-703.

Blocken, B., Deszö, G., van Beeck, J., Carmeliet, J. 2010. Comparison of calculation methods for wind-driven rain deposition on building facades. Atmospheric Environment 44(14): 1714-1725.

Blocken, B., Stathopoulos, T., Carmeliet, J., Hensen, J.L.M. 2011. Application of computational fluid dynamics in building performance simulation for the outdoor environment: an overview. Journal of Building Performance Simulation 4 (2):157-184.

Blocken, B., \& Carmeliet, J. 2012. A simplified numerical model for rainwater runoff on building facades: Possibilities and limitations. Building and Environment, 53, 59-73.

Blocken, B., Derome, D., Carmeliet, J. 2013. Rainwater runoff from building facades: A review. Building and Environment, 60, 339-361.

Blocken, B. 2014. 50 years of Computational Wind Engineering: Past, present and future. J Wind Eng Ind Aerodyn 129: 69-102.

Briggen, P.M., Blocken, B., Schellen, H.L. 2009. Wind-driven rain on the facade of a monumental tower: numerical simulation, full-scale validation and sensitivity analysis. Build Environ 44 (8):1675-1690.

Carmeliet J, Roels S, Bomberg M T. 2009. Towards Development of Methods for Assessment of MoistureOriginated Damage. chapter 28 in Moisture Control in Buildings: The Key Factor in Mold Prevention, MNL18-2nd, edited by Heinz R. Trechsel and Mark Bomberg-2nd ed., ASTM international 591-605. 
Charola, A.E., and Lazzarini, L. 1986. Deterioration of brick masonry caused by acid rain. ACS Symp. Series 318:250-258.

Choi, E.C.C. 1993. Simulation of wind-driven-rain around a building. J Wind Eng Ind Aerod 46-47:721-729.

Choi, E.C.C. 1997. Numerical modelling of gust effect on wind-driven rain. J Wind Eng Ind Aerod 72 (1):107-116.

de Freitas, S.S., Barreira, E., and de Freitas, V.P. 2013. Quantification of wind-driven rain and evaluation of façade humidification. Central European Symposium on Building Physics, September 9-11, Vienna, Austria.

Etyemezian, V., Davidson, C.I., Zufall, M., Dai, W., Finger, S., and Striegel, M. 2000. Impingement of rain drops on a tall building. Atmos Environ 34:2399-2412.

Fischer E M, Schär C. Future changes in daily summer temperature variability: driving processes and role for temperature extremes. Climate Dynamics 33:917-935, 2009.

Foroushani, M.S.S., Ge, H., and Naylor, D. 2014. Effects of roof overhangs on wind-driven rain wetting of a low-rise cubic building: A numerical study. J Wind Eng Ind Aerod 125 (0):38-51.

Franke, L., Schumann, I., van Hees, R., van der Klugt, L., Naldini, S., Binda, L., Baronio, G., van Balen, K., and Mateus, J. 1998. Damage atlas: classification and analyses of damage patterns found in brick masonry. European Commision Research report No 8, vol. 2, Fraunhofer IRB Verlag.

Hangan, H. 1999. Wind-driven rain studies. A C-FD-E approach. J Wind Eng Ind Aerod 81:323-331.

Hens, H. 2010. Wind-driven rain: from theory to reality. Paper presented at the Thermal performance of the exterior envelopes of whole buildings XI, Clearwater, Florida.

Högberg, A., Kragh, M., and van Mook, F.J.R. 1999. A comparison of driving rain measurements with different gauges. 5th Symposium of Building Physics in the Nordic Countries, Göteborg, Sweden, 24-26 August 1999.

Huang, S., and Li, Q. 2012. Large eddy simulation of wind-driven rain on tall building facades. Journal of Structural Engineering 138 (8):967-983.

ISO, 2009. Hygrothermal performance of buildings - Calculation and presentation of climatic data - Part 3: Calculation of a driving rain index for vertical surfaces from hourly wind and rain data. ISO 15927-3:2009.

Janssen, H., Blocken, B., Carmeliet, J. 2007. Conservative modelling of the moisture and heat transfer in building components under atmospheric excitation. International Journal of Heat and Mass Transfer 50(5-6): 11281140.

Kubilay, A. 2014. Numerical simulations and field experiments of wetting of building facades due to wind-driven rain in urban areas. Ph.D. thesis, ETH Zurich, Switzerland.

Kubilay, A., Derome, D., Blocken, B., and Carmeliet, J. 2013. CFD simulation and validation of wind-driven rain on a building facade with an Eulerian multiphase model. Build Environ 61:69-81.

Kubilay, A., Derome, D., Blocken, B., and Carmeliet, J. 2014a. High-resolution field measurements of wind-driven rain on an array of low-rise cubic buildings. Build Environ 78:1-13.

Kubilay, A., Derome, D., Blocken, B., and Carmeliet, J. 2014b. Numerical simulations of wind-driven rain on an array of low-rise cubic buildings and validation by field measurements. Build Environ 81:283-295.

Kubilay, A., Derome, D., Blocken, B., and Carmeliet, J. 2015a. Numerical modeling of turbulent dispersion for wind-driven rain on building facades. Environ Fluid Mech 15 (1):109-133.

Kubilay, A., Derome, D., Blocken, B., and Carmeliet, J. 2015b. Wind-driven rain on two parallel wide buildings: field measurements and CFD simulations. J Wind Eng Ind Aerod 146:11-28.

Kubilay, A, Carmeliet, J., Derome, D. 2016a. Computational fluid dynamics simulations of wind-driven rain on a mid-rise residential building with various types of facade details, J. Building Performance Simulation, doi 10.108019401493 .2016 .1152304$.

Kubilay, A., Derome, D., and Carmeliet, J. 2016b. Analysis of time-resolved wind-driven rain on an array of lowrise cubic buildings using large eddy simulation. submitted for publication to Building and Environment.

Kubilay, A., Derome,D.,Carmeliet, J. 2016c. Coupling of physical phenomena in urban microclimate: a model integrating air flow, wind-driven rain, solar radiation and transport in building materials. submitted to $\mathrm{J}$. Urban Climate.

Laan N, de Bruin K, Slenter D, Wilhelm J, Jermy M, Bonn D. 2015. Bloodstain Pattern Analysis: implementation of a fluid dynamic model for position determination of victims. Scientific Reports, 5: 11461.

Lakehal, D., Mestayer, P.G., Edson, J.B., Anquetin, S., and Sini, J.F. 1995. Eulero-Lagrangian simulation of raindrop trajectories and impacts within the urban canopy. Atmospheric Environment 29 (23):3501-3517.

Lee JB, Laan N, de Bruin K, Skantzaris G, Shahidzadeh N, Derome D, Carmeliet J, Bonn D. (2016a).Universal rescaling of drop impact on smooth and rough surfaces. J. Fluid Mechanics, 786:R4.

Lee JB, Derome D, Dolatabadi A, Carmeliet J. (2016b). Energy budget of liquid drop impact at maximum spreading: Numerical Simulations and Experiments, Langmuir, 32:1279-1288. 
Lee JB, Derome D, Guyer R, Carmeliet J. (2016c). Modeling the maximum spreading of liquid droplets impacting wetting and nonwetting surfaces, Langmuir, 32:1299-1308.

Lee JB, Derome D,Carmeliet J. (2016d). Drop impact on natural porous stones. J. Colloid and Interface Science, 469:147-156.

Lee JB, Derome D,Carmeliet J. (2016e). Absorption of impinging water droplet in porous stones. J. Colloid and Interface Science, 471:59-70.

Moonen, P., Defraeye, T., Dorer, V., Blocken, B., Carmeliet, J. 2012. Urban physics: effect of the microclimate on comfort, health and energy demand. Frontiers of Architectural Research 1(3): 197-228.

Martin, M., Defraeye T., Derome D., Carmeliet J. 2015, A film flow model for analysing gravity-driven, thin wavy fluid films, International Journal of Multiphase Flow 73:207-216.

Oke T R, Boundary Layer Climates, 2nd ed., Methuen, London, 1987.

Ruyer-Quil, C., \& Manneville, P. 2000. Improved modeling of flows down inclined planes. The European Physical Journal B, 15:357-369.

Ruyer-Quil, C., \& Manneville, P. 2002. Further accuracy and convergence results on the modeling of flows down inclined planes by weighted-residual approximations. Physics of Fluids, 14:170-183.

Schär C, Vidale P L, Lüthi D, Frei C, Häberli C, Liniger M A, Appenzeller C. The role of increasing temperature variability in European summer heatwaves. Nature 427:332-336, 2004.

Silvi, N. 1985. The rewetting of an inclined solid surface by a liquid. Physics of Fluids (1958-1988), 28, 5-7.

Straube JF, Burnett EFP. Simplified prediction of driving rain on buildings. Proc. of the International Building Physics Conference, Eindhoven, The Netherlands, 18-21 September 2000, 375-382

Sumner, G.N. 1981. The nature and development of rainstorms in Coastal East Africa. J Climatol 1 (2):131-152.

Tang, W., and Davidson, C.I. 2004. Erosion of limestone building surfaces caused by wind-driven rain: 2. numerical modeling. Atmos Environ 38 (33):5601-5609.

Tang, W., Davidson, C.I., Finger, S., and Vance, K. 2004. Erosion of limestone building surfaces caused by winddriven rain: 1. Field measurements. Atmos Environ 38 (33):5589-5599.

Teasdale-St-Hilaire, A. and Derome, D. 2007. Comparison of experimental and numerical results of wood-frame wall assemblies wetted by simulated wind-driven rain infiltration. Energy and Buildings 39: 1131-1139.

Uijlenhoet, R. and Stricker, J.N.M. 1999. A consistent rainfall parameterization based on the exponential raindrop size distribution. Journal of Hydrology 218 (3-4): 101-127.

Urkhardt, M., Zuleeg, S., Vonbank, R., Bester, K., Carmeliet, J., Boller, M., Wangler T. (2012) Leaching of biocides from Façades under natural weather conditions. Environmental Science and Technology 46 (10): 54975503.

Van Balen, K. 1996. Expert system for evaluation of deterioration of ancient brick masonry structures. Sci Total Environ 189:247-254.

Van den Brande, T., Blocken, B., \& Roels, S. 2013. Rain water runoff from porous building facades: Implementation and application of a first-order runoff model coupled to a HAM model. Building and Environment, 64:177186.

van der Hoven, I. 1957. Power spectrum of horizontal wind speed in the frequency range from 0.0007-900 cycles per hour. J Meteo 14 (2):160-164.

van Hooff, T., Blocken, B., and van Harten, M. 2011. 3D CFD simulations of wind flow and wind-driven rain shelter in sports stadia: Influence of stadium geometry. Build Environ 46 (1):22-37.

van Mook, F.J.R. 2002. Driving rain on building envelopes. In.: Ph.D. thesis, Eindhoven University of Technology, Eindhoven, The Netherlands. 